\title{
HISTÓRIA MEDIEVAL NA AMAZÔNIA: TRAJETÓRIA, DESAFIOS E PERSPECTIVAS
}

\section{MEDIEVAL HISTORY IN THE AMAZON: TRAJECTORY, CHALLENGES AND PERSPECTIVES}

Douglas Mota Xavier de Lima

Universidade Federal do Oeste do Pará

Resumo: Nas últimas décadas houve uma significativa expansão dos estudos medievais no Brasil. Centrando a observação na região Norte do Brasil, o presente artigo se propõe a apresentar um inventário da inserção institucional da História Medieval, indicando as características e os principais desafios para a estruturação do campo na região. Em seguida, passamos a tecer algumas considerações sobre os projetos desenvolvidos atualmente e as perspectivas para a área.
Abstract: In the last decades, there was a significant expansion of the medieval studies in Brazil. Focusing the observation on the North of Brazil, this article aims to present an inventory of the institutional insertion of Medieval History, indicating the characteristics and the main challenges for structuring the field in the area. Then, we started to weave some considerations on the projects currently developed and the perspectives for the area.
Palavras-chave: História Medieval. Amazônia. Historiografia.
Keywords: Medieval History. Amazon. Historiography. 
Os estudos medievais no Brasil e, especificamente, a História Medieval, têm uma trajetória recente no meio acadêmico brasileiro. Iniciada na Universidade de São Paulo e com a primeira tese dedicada ao período sendo defendida em 1942, a área conhece atualmente um crescimento significativo, movimento de estruturação e de expansão ocorrido, sobretudo, entre os anos 80 e 90 . Os balanços acerca do tema chamam atenção para: a fundação do primeiro setor dedicado à História Medieval no âmbito de um programa de pós-graduação brasileiro, o setor de História Antiga e Medieval do PPGHUFF, em 1988; a constituição do Grupo de Trabalho de História Medieval da Associação Nacional de História (Anpuh), também em 1988; e o estabelecimento da Associação Brasileira de Estudos Medievais (ABREM), em 1996. Esses mesmos anos foram ainda marcados pela ampliação das pós-graduações no país, pelo financiamento de pesquisas de iniciação científica e pela concessão de bolsas sanduíche, ações que favoreceram o desenvolvimento de monografias, dissertações e teses dedicadas à área ${ }^{1}$.

Não obstante, ainda que o cenário indique o crescimento exponencial da História Medieval no Brasil, as recentes polêmicas surgidas em torno da primeira versão da Base Nacional Comum Curricular constituem um alerta acerca dos desafios que permanecem envolvendo o campo de estudo ${ }^{2}$. Nesse sentido, é possível traçar duas linhas

\footnotetext{
${ }^{1}$ Existe um número relevante de artigos que se dedicaram a fazer um balanço dos estudos medievais no Brasil. Desta maneira, limitamo-nos a indicar apenas alguns que poderão oferecer uma visão ampla acerca do tema e introduzir o leitor nos principais problemas relativos ao campo: ALMEIDA, Néri de Barros. La formation des médiévistes dans le Brésil contemporain: bilans et perspectives (1985-2007). In: Bulletin du Centre d'études médiévales d'Auxerre, 12 (2008); BASTOS, Mario Jorge da Motta \& RUST, Leando Duarte. Translatio Studii. A História medieval no Brasil. In: Signum, 10 (2008), p.163-188; ASFORA, Wanessa et al. Faire l'histoire du Moyen Âge au Brésil. In: Bulletin du Centre d'études médiévales d'Auxerre, 12 (2008), p.125-144; FRANCO JÚNIOR, Hilário, BASTOS, Mario Jorge da Motta \& RUST, Leando Duarte. Historiographie et médiévistique brésilienne: une aproche d'ensemble. In: MAGNANI, Eliana (dir.). Le Moyen Âge vu d'ailleurs: voix croisées d'Amérique latine et d'Europe. Dijon: Editions Universitaires de Dijon, 2010, p.39-52; SILVA, Andréia Cristina Lopes Frazão da. Os estudos medievais no Brasil e o diálogo interdisciplinar. In: Medievalis, Vol. 1 (2), 2013, p.1-15. Em 2003, o professor José Rivair Macedo publicou um importante catálogo sobre as teses e dissertações defendidas no âmbito da História e das demais áreas também dedicadas ao estudo do medievo. A obra continua sendo um material de grande relevância e que oferece um panorama das pesquisas realizadas no Brasil. Cf.: MACEDO, José Rivair. Os estudos medievais no Brasil. Catálogo de dissertações e teses: Filosofia, História e Letras (1990-2002). Porto Alegre: UFRGS, 2003.

${ }^{2} \mathrm{O}$ texto da Base Nacional Comum Curricular (BNCC) disponibilizado para consulta pública em setembro de 2015, gerou uma série de discussões pelo país. O material pode ser visto em site específico (http://basenacionalcomum.mec.gov.br), e entre as críticas lançadas à versão da BNCC, destacamos a questão do ensino de História e, especificamente das áreas de História Antiga e História Medieval. Os posicionamentos contrários podem ser lidos no ofício da Associação Nacional de Pós-graduação e Pesquisa em Educação (ANPED), disponível em: http://www.anped.org.br; em nota da Associação Nacional de História (ANPUH), disponível em: http://site.anpuh.org; em nota da Associação Nacional de Pesquisadores e Professores de História das Américas (ANPLAC), disponível em: http://anphlac.fflch.usp.br/; em carta da Associação Brasileira de Estudos Medievais (ABREM), disponível em: http://www.abrem.org.br. Os
} 
interpretativas, uma que compreende os inegáveis avanços da área nos últimos anos, e outra que lembra as importantes resistências ainda enfrentadas, as quais, por vezes, questionam a própria existência do campo ou as contribuições que tal estudo poderia dar ao conhecimento histórico das novas gerações no Brasil. Como tentaremos expor ao longo do texto, há também uma interessante variante no debate sobre a História Medieval no país. Consideramos que a trajetória de afirmação dos estudos não pode ser generalizada, visto que existem diferenças marcantes entre as regiões e estas se manifestam, principalmente, nos dados da região Norte do Brasil. Desta maneira, problematizar o crescimento da área e os desafios que ainda se apresentam a partir da região amazônica poderá oferecer novas nuances no que se refere à situação nacional.

Do mesmo modo, indica-se que uma parcela das resistências apontadas envolve a discussão sobre o lugar da História Medieval, e não menos dos medievalistas, no âmbito das Ciências Humanas, da História e, em especial, do Ensino de História. Em linhas gerais, levanta-se o problema dos motivos de se estudar Idade Média na atualidade. Na última década a questão motivou a realização de diferentes encontros acadêmicos e a publicação de importantes estudos ${ }^{3}$. Todavia, no Brasil a discussão ainda é atravessada pela ideia de que disciplinas como História Antiga, História Medieval ou mesmo História Moderna, promoveriam o olhar do colonizador, reforçando uma visão eurocêntrica de história na qual o Brasil, a América e a África ganham sentido a partir da Europa.

Dito isso, passa-se a considerar a trajetória do campo no Brasil, em especial, na região que orienta o presente artigo. Em texto publicado no ano de 2002, Carlos Roberto Nogueira lembrava o descompasso existente entre os estudos medievais nas regiões Sul, Sudeste e Centro-Oeste, e nas regiões Norte e Nordeste:

No Norte e Nordeste brasileiros, mapeamos a ausência de centros desse tipo [voltados aos estudos medievais], até setembro de 2002, motivada quer por uma

professores de História Antiga e Medieval das regiões Norte e Nordeste também se mobilizaram contrariamente à BNCC, e o posicionamento coletivo pode ser visto em: http://anpuhro.blogspot.com.br. Atualmente (janeiro de 2017), a BNCC encontra-se em processo de finalização e em sua terceira versão.

${ }^{3}$ Estes questionamentos estão no cerne de trabalhos como: MORSEL, Joseph. L'Histoire (du Moyen Âge) est un sport de combat... Réflexions sur les finalités de l'Histoire du Moyen Âge destinées à une société dans laquelle même les étudiants d'Histoire s'interrogent. Paris: LAMOP, 2007; Être historien du Moyen Âge au XXIe siècle. XXXVIIIe congrès de la SHMESP. Paris: Publications de la Sorbonne, 2008; MEHÚ, Didier, ALMEIDA, Néri de Barros \& SILVA, Marcelo Cândido da (dir.) Pourquoi étudier le Moyen Âge? Les médiévistes face aux usages sociaux du passé. Actes du coloque tenu à l'Université de São Paulo du 7 au 9 de mai 2008. Paris: Publications de la Sorbonne, 2012.

\section{1}


carência de investigadores titulados, derivada de uma instalação ainda recente dos cursos de humanidades, ou mesmo da acima citada 'visão pragmática' e presentista que exclui a Idade Média dos currículos universitários. Ao que sabemos apenas a Universidade Federal da Bahia, a Universidade Estadual do Sudoeste da Bahia e a Universidade Federal de Pernambuco, possuem docentes titulados na área de História Medieval ${ }^{4}$.

Exemplo que corrobora os apontamentos de Nogueira é o caso do curso de História implantado em 1955, na antiga Faculdade de Filosofia, Ciências e Letras do Pará, e depois incorporado à Universidade Federal do Pará (UFPA), em 1957. No ano de 1988, o curso constituiu-se como departamento autônomo, momento que significou o crescimento do número de pesquisas desenvolvidas até então. Em 1997, o departamento estruturou a área de investigação em História Social da Amazônia, linha que orientou a criação do Programa de Pós-graduação em História Social da Amazônia, em 2004 ${ }^{5}$. É sintomático que o curso da UFPA, um dos mais tradicionais e consolidados da região, tenha conhecido uma estruturação tão recente e concentrado suas investigações nos estudos amazônicos. No que pese a importância da instituição como referência na história da Amazônia, destaca-se que tal inclinação resultou na praticamente inexistência de trabalhos sobre a antiguidade e o medievo. Outro elemento que chama atenção é a presença das disciplinas "História Antiga" e "História Medieval" no projeto político pedagógico do referido curso. Enquanto a última grade previa a oferta destas no primeiro e no segundo semestre da graduação, respectivamente, a partir da reformulação de 2011 as disciplinas deixaram de existir e deram lugar a outras, denominadas "Formação do Pensamento Clássico" e "História do Feudalismo"6, o que mais uma vez sinaliza a redução do espaço da História Antiga e Medieval no referido curso.

Retornando aos aspectos específicos da História Medieval, lembra-se que a institucionalização da área ocorreu no interior das universidades e, em especial, através dos programas de pós-graduação. Essa característica do campo é fundamental por

\footnotetext{
${ }^{4}$ NOGUEIRA, Carlos Roberto Figueiredo. Os estudos medievais no Brasil de hoje. In: Medievalismo, Madrid, v.4, n.4, 2002, p.293.

${ }^{5} \mathrm{O}$ histórico do curso de História da UFPA pode ser acessado em:

http://www.ufpa.br/historia/index.php?option=com content\&view=article\&id=2\&Itemid=2 $\quad$ (acesso 23/10/2015).

${ }^{6}$ Os referidos projetos político pedagógicos podem ser acessados em :

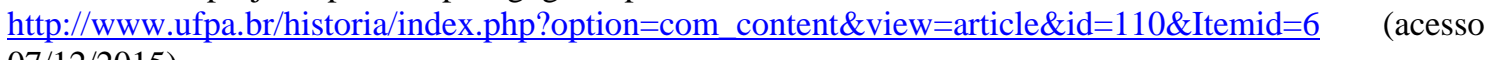
07/12/2015).
} 
contrastar com outros países e para compreender que a análise da produção de pesquisas na área não pode ser dissociada da estruturação institucional dos cursos de História. Dito isso, destacam-se os dados levantados por Wanessa Asfora, Eduardo Aubert e Gabriel Castanho em 2008:

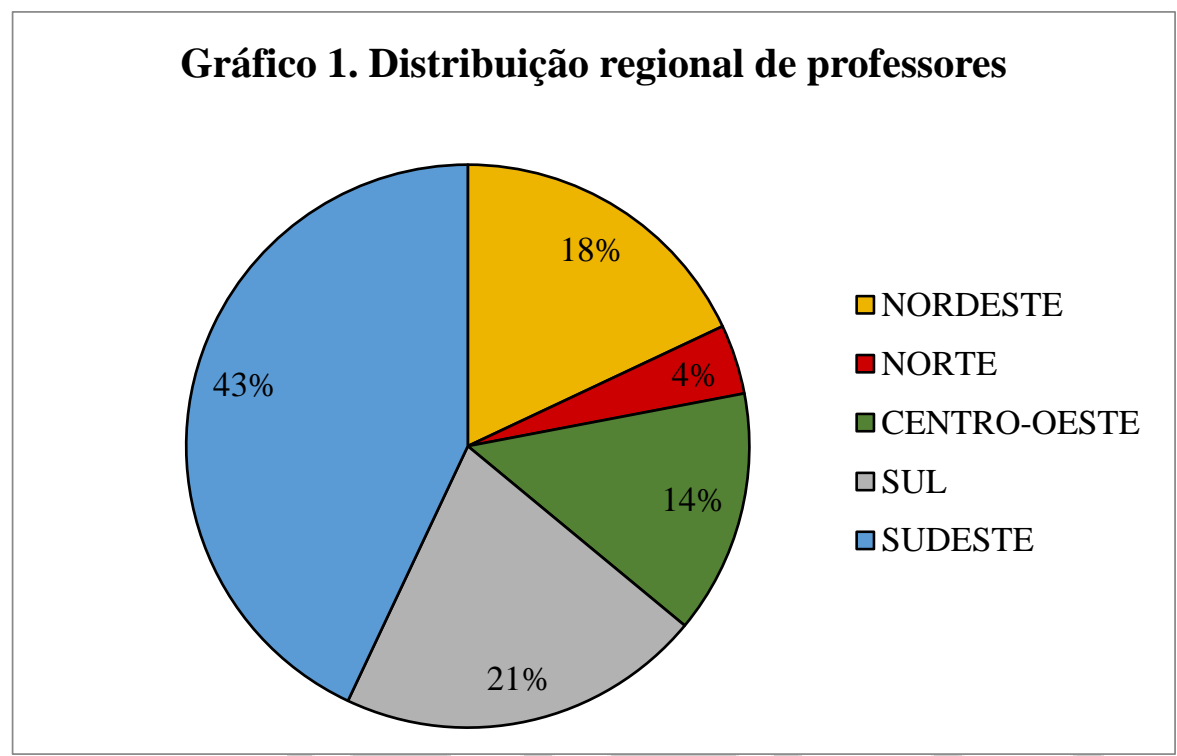

Fonte: ASFORA, Wanessa; AUBERT, Eduardo \& CASTANHO, Gabriel. Faire l'histoire du Moyen Âge au Brésil. In: Bulletin du Centre d'études médiévales d'Auxerre, 12 (2008), p. 3.

\section{Gráfico 2. Distribuição regional de medievalistas}

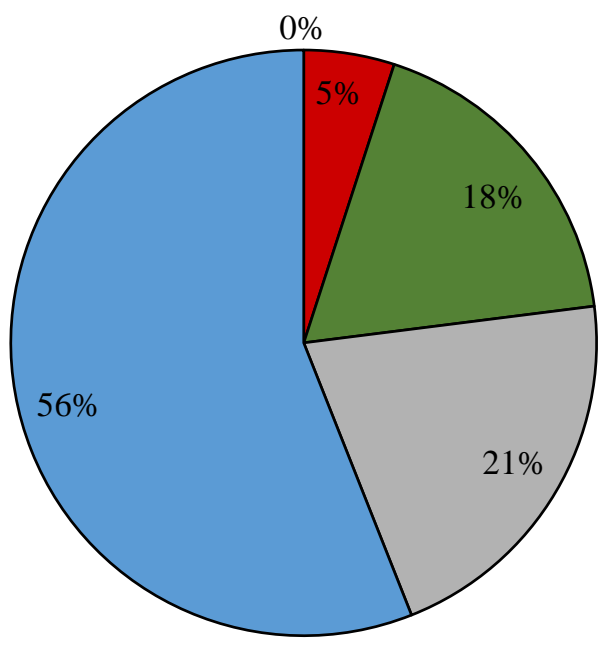

口NORDESTE

$\square$ NORTE 口CENTRO-OESTE $\square$ SUL 口SUDESTE

Fonte: ASFORA, Wanessa; AUBERT, Eduardo \& CASTANHO, Gabriel. Faire l'histoire du Moyen Âge au Brésil. In: Bulletin du Centre d'études médiévales d'Auxerre, 12 (2008), p. 3.

Nota-se a partir dos gráficos 1 e 2 a concentração de professores e, especificamente, de medievalistas, na região Sudeste, porcentagem que se amplia quando 
somada aos números da região Sul. Constata-se no primeiro gráfico que os professores de História Medieval nas regiões Centro-Oeste (3 Estados e 1 Distrito Federal) e Norte (7 Estados) somam 18\%, montante que ainda assim é inferior ao conjunto de profissionais presentes nos três estados da região Sul (21\%). No segundo gráfico, observa-se que, em comparação às demais regiões, o Sudeste concentra mais da metade dos medievalistas do Brasil.

Os autores consideram que este quadro resulta de uma conjunção de razões, dentre as quais destacam-se duas: a existência de programas de pós-graduação em História no Sul e Sudeste desde os anos 1980, aspecto que contrasta com a situação da região Norte, com programas iniciados nos anos 2000; a percepção de que as linhas de pesquisa favorecidas, sobretudo pelos programas mais recentes, privilegiam a História do Brasil e mesmo a História Regional, afastando-se das perspectivas mais universalistas das universidades e programas mais antigos?

Em vista desses apontamentos, faz-se uma breve exposição acerca do quadro institucional da região Norte, focando nos cursos de História existentes, no perfil dos docentes, nos programas de pós-graduação e nos grupos de pesquisa dedicados aos estudos medievais.

\section{O quadro institucional da História Medieval na região Norte}

Atualmente, constam 25 instituições públicas e privadas oferecendo cursos de graduação em História presenciais na região amazônica, com o predomínio de cursos de licenciatura $^{8}$. Acrescenta-se que esse número deve ser observado considerando o significativo investimento na abertura de novas instituições e unidades universitárias na última década, em especial através do Programa de Apoio a Planos de Reestruturação e Expansão das Universidades Federais (REUNI) ${ }^{9}$. A fim de visualizar o impacto deste

\footnotetext{
${ }^{7}$ ASFORA, Wanessa; AUBERT, Eduardo \& CASTANHO, Gabriel. Faire l'histoire du Moyen Âge au Brésil. In: Bulletin du Centre d'études médiévales d'Auxerre, 12 (2008), p. 3-5.

${ }^{8}$ Acre: UFAC; Amapá: UNIFAP, FAMA; Amazonas: UEA, UNINILTONLINS, UFAM, UNINORTE; Pará: FAI, UFOPA, UFPA, UNIFESSPA, ESMAC, FAAM, UEPA, UNAMA, FCAT, FAINTIPI, FIBRA; Rondônia: FAROL, UNIR, FIAC; Roraima: UERR, UFRR; Tocantins: UFT, FIESC. Os dados estão disponíveis em: http://emec.mec.gov.br.

${ }^{9}$ Acerca do REUNI, ver: http://reuni.mec.gov.br.
} 
programa governamental, destaca-se o caso dos Institutos Federais de Ensino Superior (IFES) do estado do Pará.

O estado conta no momento com quatro IFES: Universidade Federal Rural da Amazônia (UFRA), Universidade Federal do Pará (UFPA), Universidade Federal do Oeste do Pará (UFOPA) e Universidade Federal do Sul e Sudeste do Pará (UNIFESSPA), existindo cursos de História nas três últimas. Como pontuado anteriormente, o curso da UFPA remonta aos anos 50, localizado na cidade de Belém. Nos anos 80, a universidade iniciou o seu processo de interiorização, constituindo campis em cidades como Cametá e Bragança, ambas com oferta atual de cursos de História. Constata-se que, nos dois casos, foi a partir do REUNI que os cursos foram criados, em 2007, na cidade de Cametá ${ }^{10}$ e, em 2010, em Bragança ${ }^{11}$. Soma-se ainda que, em ambos os cursos, existem professores mestres e doutores trabalhando na grande área de História Antiga e Medieval.

A UFOPA foi fundada no ano de 2009, tendo o curso de Licenciatura Integrada em História e Geografia iniciado suas atividades em 2011 e, em 2015, ocorrido o desmembramento em Licenciatura em História e Licenciatura em Geografia. No ano de 2014, através de concurso público, o curso contratou professor para a cadeira de História Antiga e Medieval.

A Universidade Federal do Sul e Sudeste do Pará (UNIFESSPA) foi criada em 2013, tendo o curso de Licenciatura em História iniciado suas atividades em 2014. Diferente da UFOPA, a UNIFESSPA dispõe de mais de uma unidade universitária com a oferta do curso de História, localizando-se nas cidades de Marabá e de Xinguara. Não obstante, em nenhuma das unidades há professor com formação dedicada às áreas de História Antiga e Medieval, ainda que nos últimos anos venham ocorrendo diferentes concursos para a composição do quadro docente.

Em linhas gerais, percebe-se que a institucionalização dos cursos de graduação em História no estado do Pará é deveras recente, sendo a exceção o curso da UFPA/Belém. A compreensão desse processo requer que se remeta a discussão ao movimento de reestruturação e expansão universitária das últimas décadas, manifesto no REUNI, o qual enfatizou a abertura de cursos de licenciatura. Outro aspecto relevante, ainda que não exclusivo do estado e da região amazônica, é o fato dos concursos

\footnotetext{
${ }^{10}$ Ver: http://www.campuscameta.ufpa.br/documentos/FACHTO/PPC HISTORIA.pdf.

${ }^{11}$ Ver: http://www.campusbraganca.ufpa.br/index.php/historico.
}

\section{5}


associarem as áreas de História Antiga e de História Medieval, formando uma cadeira única que abarca, em alguns casos, desde a antiguidade oriental até os séculos XIV e XV no Ocidente medieval. Além disso, sublinha-se que a área de Antiga e Medieval, por vezes, limita-se a apenas um docente por instituição, como pode ser notado no Quadro abaixo.

Quadro 1. Distribuição e perfil de docentes de História Medieval na região Norte por Universidades Federais e Estaduais

\begin{tabular}{|c|c|c|c|c|c|}
\hline $\begin{array}{c}\text { DOCENT } \\
\text { E }\end{array}$ & $\begin{array}{l}\text { UNIVERSIDAD } \\
\text { E }\end{array}$ & $\begin{array}{c}\text { ÁREA DE } \\
\text { ATUAÇÃ } \\
\text { O }\end{array}$ & $\begin{array}{c}\text { ÁREA DE } \\
\text { FORMAÇÃOO }\end{array}$ & $\begin{array}{l}\text { TITULAÇÃ } \\
\text { O }\end{array}$ & $\begin{array}{c}\text { PROJETO } \\
\text { DE } \\
\text { PESQUIS } \\
\text { A NA } \\
\text { ÁREA } \\
\end{array}$ \\
\hline Não há (1) & UFAC & $\mathrm{X}$ & $X$ & $\mathrm{X}$ & $\mathrm{X}$ \\
\hline $\begin{array}{l}\text { Renan } \\
\text { Marques } \\
\text { Birro }\end{array}$ & UNIFAP & Medieval & Medieval & Mestrado & Sim \\
\hline $\begin{array}{c}\text { Sínval } \\
\text { Carlos } \\
\text { Mello } \\
\text { Gonçalves }\end{array}$ & UFAM & Medieval & Medieval & Doutorado & Sim \\
\hline $\begin{array}{l}\text { Macário } \\
\text { Lopes de } \\
\text { Carvalho } \\
\text { Júnior }\end{array}$ & UEA & $\begin{array}{l}\text { Antiga e } \\
\text { Medieval }\end{array}$ & & Mestrado & Sim \\
\hline $\begin{array}{l}\text { Jorge Paulo } \\
\text { dos Santos } \\
\text { Watrin (2) }\end{array}$ & UFPA (Belém) & Medieval & $\begin{array}{l}\text { Educação/Ciência } \\
\text { s da Religião }\end{array}$ & Doutorado & Não \\
\hline $\begin{array}{l}\text { Roberta } \\
\text { Alexandrin } \\
\text { a Silva }\end{array}$ & UFPA (Bragança) & $\begin{array}{l}\text { Antiga e } \\
\text { Medieval }\end{array}$ & Antiga & Doutorado & Sim \\
\hline $\begin{array}{l}\text { Thiago } \\
\text { Azevedo } \\
\text { Porto }\end{array}$ & UFPA (Bragança) & $\begin{array}{l}\text { Antiga e } \\
\text { Medieval }\end{array}$ & Medieval & Mestrado & Sim \\
\hline $\begin{array}{c}\text { Josué } \\
\text { Berlesi }\end{array}$ & UFPA (Cametá) & $\begin{array}{c}\text { Antiga e } \\
\text { Medieval }\end{array}$ & Antiga & Mestrado & Sim \\
\hline $\begin{array}{c}\text { Douglas } \\
\text { Mota } \\
\text { Xavier de } \\
\text { Lima }\end{array}$ & UFOPA & $\begin{array}{l}\text { Antiga e } \\
\text { Medieval }\end{array}$ & Medieval & Doutorado & Sim \\
\hline Não há (1) & UEPA (Belém) & $\mathrm{X}$ & $\mathrm{X}$ & $\mathrm{X}$ & $\mathrm{X}$ \\
\hline Não há (1) & $\begin{array}{c}\text { UNIFESSPA } \\
\text { (Marabá) }\end{array}$ & $\mathrm{X}$ & $\mathrm{X}$ & $\mathrm{X}$ & $\mathrm{X}$ \\
\hline Não há (1) & $\begin{array}{l}\text { UNIFESSPA } \\
\text { (Xinguara) }\end{array}$ & $\mathrm{X}$ & $\bar{X}$ & $\mathrm{X}$ & $\mathrm{X}$ \\
\hline $\begin{array}{c}\text { Verônica } \\
\text { Aparecida } \\
\text { Silveira } \\
\text { Aguiar }\end{array}$ & UNIR & $\begin{array}{l}\text { Antiga e } \\
\text { Medieval }\end{array}$ & Medieval & Doutorado & Sim \\
\hline Não há (1) & UFRR & $\mathrm{X}$ & $\mathrm{X}$ & $\mathrm{X}$ & $\mathrm{X}$ \\
\hline $\begin{array}{c}\text { Rodrigo } \\
\text { Poreli } \\
\text { Bueno } \\
\end{array}$ & UFT & Medieval & $\begin{array}{c}\text { História do } \\
\text { Brasil/Filosofia }\end{array}$ & Doutorado & Não \\
\hline
\end{tabular}


Fonte: Elaboração própria.

Legenda: (1) = Nos casos dessas instituições, não foi encontrado professor responsável pela cadeira de História Medieval. Acrescenta-se que na UFAC consta o professor Dr. Marcelo da Silva Murilo, com formação em Ensino e com tese acerca da Idade Média nos Livros Didáticos. Contudo, os dados do currículo lattes do professor não permitem afirmar que ele leciona História Medieval, assim como indicam a atuação do mesmo em disciplinas e projetos de pesquisa no âmbito geral da Educação e do Ensino de História

(Cf.: http://lattes.cnpq.br/2949682548644140).

(2) = No site da Faculdade de História da UFPA, o referido consta como único docente dedicado à História Medieval (Cf.: http://www.ufpa.br/historia)

O Quadro 1 permite ampliar a questão da institucionalização da História Medieval na região Norte. Primeiramente, reforça-se a associação entre as áreas de Antiga e Medieval, tal como se apresenta na tabela de distribuição das áreas do conhecimento da CAPES $^{12}$. Quiçá o principal problema da aplicação deste critério na constituição das cadeiras universitárias seja a expectativa de um perfil generalista que não se aplica à formação acadêmica. O caso do PPGH-UFF, como um dos principais programas de formação de pós-graduação em História no país, pode ser elucidativo sobre o assunto. Ainda que exista o setor temático de Antiga e Medieval desde 1988 - o mais antigo do Brasil, como foi citado -, a seleção de mestrado e doutorado ocorre com bancas e avaliações específicas para cada área, explorando as particularidades de cada campo. Além disso, no quadro da produção de teses e dissertações no Brasil, é comum que os trabalhos se concentrem numa das quatro grandes civilizações da Antiguidade Mesopotâmia, Egito, Grécia e Roma - ou, no caso dos medievalistas, num dos grandes períodos da Idade Média - a Alta, Central e Baixa Idade Média. Há variações nesse panorama, todavia, o aspecto central que buscamos enfatizar é que não se formam pesquisadores em “Antiga e Medieval”. Os dados expostos na tabela indicam a tendência para que as instituições tenham apenas um docente para a área e a existência de um número maior de medievalistas atuando nas cadeiras de Antiga e Medieval. Se isso pode oferecer bons indicativos para os estudos medievais, o que dizer para assiriólogos, egiptólogos, helenistas e latinistas?

Da mesma maneira, constatam-se outros elementos relevantes. O quadro aponta para um conjunto de professores jovens, com formação ocorrida na última década e que ainda estão em fase de doutoramento, sendo seis os casos dos docentes já doutores na região. Não menos importante, os dados disponíveis na plataforma lattes sustentam que

12 Disponível em: http://www.capes.gov.br/avaliacao/instrumentos-de-apoio/tabela-de-areas-doconhecimento-avaliacao (acesso em: 26/10/2015). 
a maior parcela dos professores indicados está desenvolvendo projetos de pesquisa acerca do medievo, o que pode favorecer o enraizamento da área nos próximos anos.

Quanto aos programas de pós-graduação, espaço privilegiado para o desenvolvimento de pesquisas no universo acadêmico nacional, os dados reforçam o contraste entre a região e o restante do país. De acordo com o site da CAPES ${ }^{13}$, constam três (3) programas de História em toda a região amazônica. O Programa de Pós-graduação em História Social da Amazônia da UFPA é o mais antigo, tendo iniciado suas atividades em 2004. Em 2006, teve início as atividades do Programa de Pós-graduação em História da UFAM, programa que se destaca como o único a desenvolver pesquisas em História Medieval. Trata-se das orientações levadas a cabo pelo Prof. Dr. Sínval Gonçalves, na linha de pesquisa "Cultura e Representações", e que nos últimos anos formou cinco (5) mestres em História com estudos acerca do período medieval ${ }^{14}$. Ainda mais recente que os anteriores, o Programa de Pós-graduação em História e Estudos culturais da UNIR, com turmas desde 2012, tem suas linhas de pesquisa direcionadas aos estudos amazônicos. Fora do âmbito específico da História, convém acrescentar o Programa Linguagens e Saberes na Amazônia da UFPA/Bragança. Neste a Prof. a Dr. ${ }^{a}$ Roberta Alexandrina da Silva tem orientado dissertações em História dedicadas ao mundo antigo e medieval.

\footnotetext{
${ }^{13}$ Disponível em: http://www.capes.gov.br/cursos-recomendados.

14 As referidas orientações podem ser acompanhadas no currículo lattes do professor: http://lattes.cnpq.br/3690012351335425.
}

\section{8}




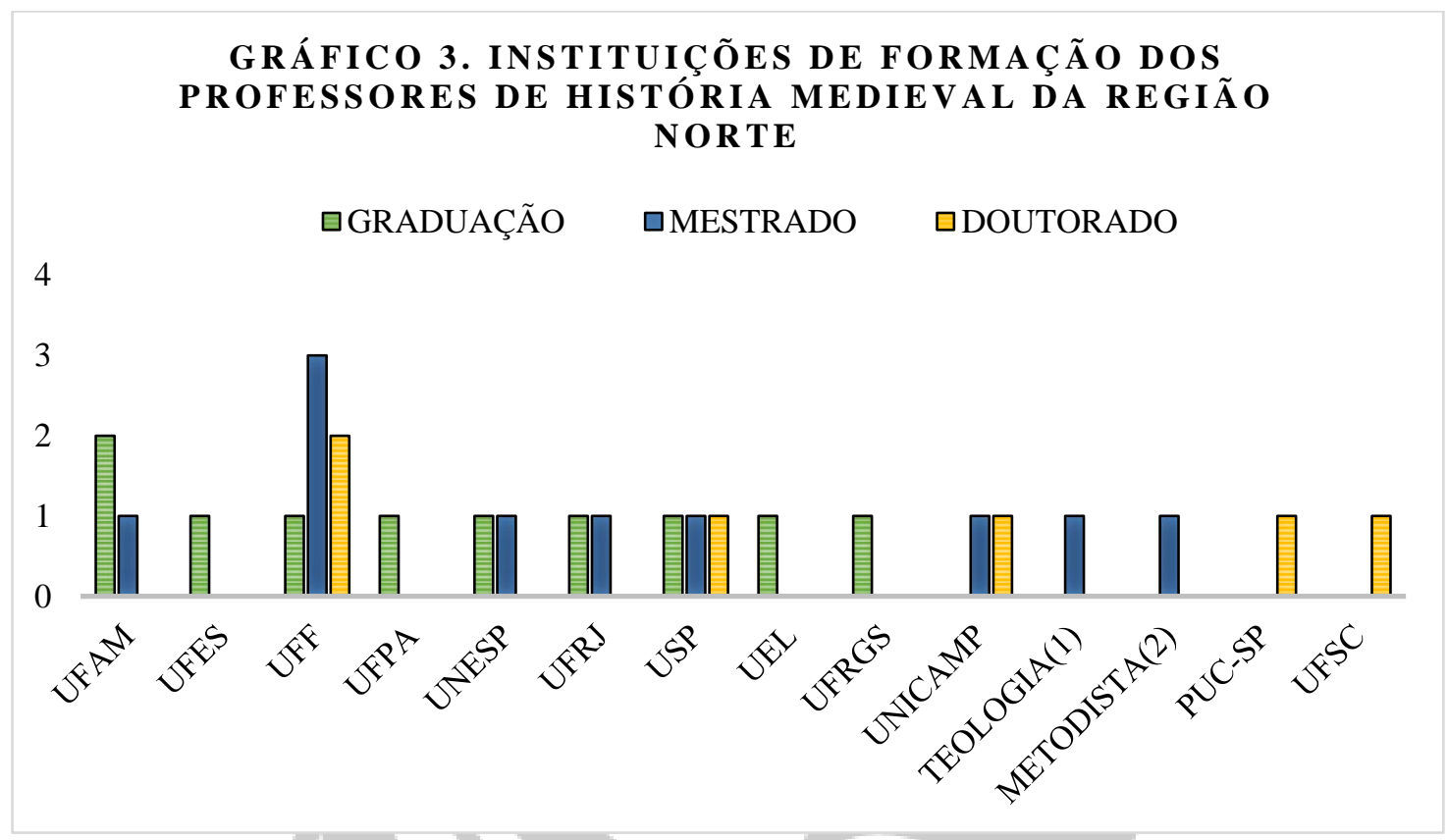

Fonte: Elaboração própria a partir de consulta na Plataforma Lattes.

Legenda: (1) = Escola Superior de Teologia; (2) = Universidade Metodista de Piracicaba

Ao relacionar o cenário da Pós-graduação em História na região Norte com o quadro 1, nota-se que apenas o Prof. Me. Macário Carvalho Júnior fez graduação e mestrado na região Norte, no caso, na Universidade Federal do Amazonas, sob orientação do Prof. Dr. Sínval Gonçalves. Tal situação revela outra particularidade da região, consequência das limitações de espaços institucionais de formação, que é a migração de professores formados em outras regiões do país, especialmente nos programas de mestrado e doutorado do Sudeste, para ocuparem as vagas universitárias existentes na Amazônia, como observa-se no Gráfico 3.

Em levantamento realizado no Diretório de Grupos de Pesquisa no Brasil do CNPq (Gráfico 4) $)^{15}$, constata-se a existência de quarenta e dois (42) grupos que apresentam o termo "medieval" em suas linhas de pesquisa e são da grande área "História". Estes se encontram distribuídos por todas as regiões do país, no entanto permanece a concentração apontada nos textos de Nogueira (2002) e Asfora, Aubert e Castanho (2008). O Sudeste agrega o maior número de grupos (16), sendo as universidades do Rio de Janeiro as que congregam a maior parcela destes, com 7 grupos.

\footnotetext{
${ }^{15}$ O levantamento foi realizado no dia 24 de outubro de 2015, levando-se em consideração o termo "medieval". A busca foi aplicada aos itens "nome do grupo", "nome da linha de pesquisa" e "palavra-chave da linha de pesquisa", com a utilização dos filtros "ciências humanas" para a Grande área e "história" para a Área.
} 
Chama atenção que o Nordeste e o Centro-Oeste tenham o mesmo número de grupos de pesquisa cadastrados (7), ao passo que a região Norte conta com apenas 4 grupos.

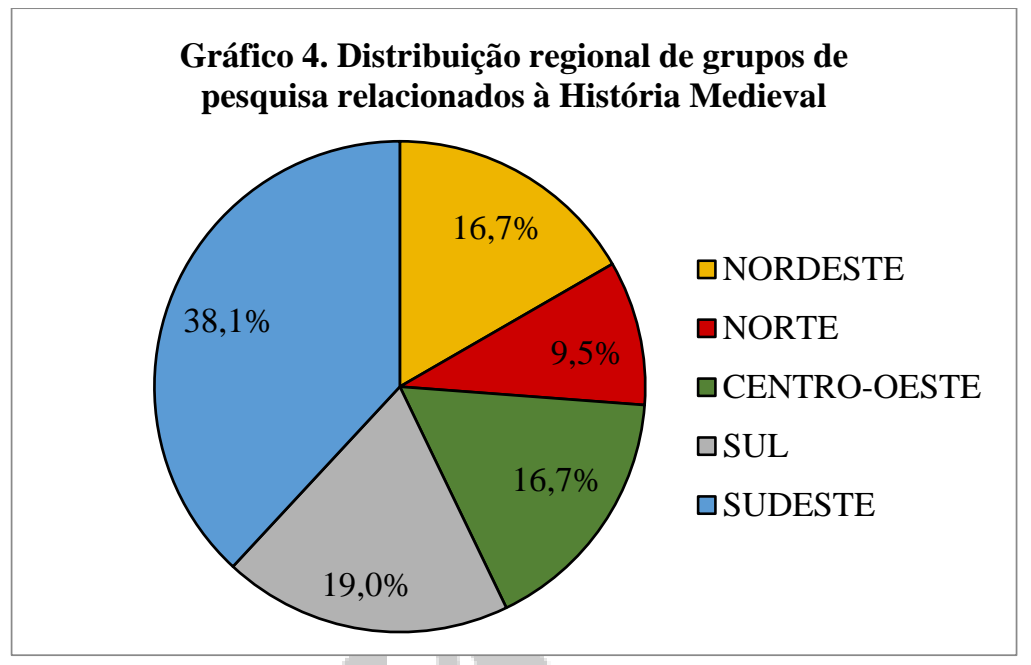

Fonte: Elaboração própria a partir do Diretório de Grupos de Pesquisa no Brasil do $\mathrm{CNPq}$

Tais números são parciais e um estudo mais detalhado poderia oferecer uma visão mais qualitativa dos grupos em questão, distinguindo grupos compostos por medievalistas de grupos generalistas e sem especialistas na área. De qualquer maneira, a fim de observar as nuances existentes, passamos a uma exposição acerca dos grupos de pesquisa do Norte do país.

O grupo de pesquisa mais antigo da região Norte é o "Imaginário e Cultura no Ocidente Medieval"16, coordenado pelo Prof. Dr. Sínval Carlos Gonçalves na Universidade Federal do Amazonas (UFAM). Fundado em 2008, o grupo conta com diferentes linhas de pesquisa e tem como particularidades a inserção na Pós-graduação em História da UFAM e a ligação com o Scriptorium-Laboratório de Estudos Medievais e Ibéricos, sediado na Universidade Federal Fluminense, um dos mais antigos núcleos de pesquisa em História Medieval do Brasil - fundado em 1996 - e que tem no Prof. Dr. Sínval Gonçalves o seu vice-líder. Este aspecto tem favorecido, entre outras coisas, a realização de eventos conjuntos, resultando na vinda de pesquisadores nacionais e internacionais ao Amazonas, como no Colóquio "Ler, escrever e narrar na Idade Média" (2009), que contou com a participação da helenista Pauline Schmitt Pantel (Paris I

16 Disponível em: http://dgp.cnpq.br/dgp/espelhogrupo/9814950495689021 (último acesso em: 24/10/2015). 
Phantéon-Sorbonne) e dos medievalistas Monique Goullet (Université Paris I Phanthéon Sorbonne - LAMOP) e Jean-Claude Schmitt (EHESS - GAHOM) ${ }^{17}$.

Contrastando com o caso da UFAM, os demais grupos de pesquisa da região Norte são de constituição extremamente recente. O grupo "Oiapock - Laboratório de História Social" ${ }^{\prime 18}$, foi fundado em 2014 e caracteriza-se como um núcleo que agrega os professores do campus Binacional de Oiapoque da Universidade Federal do Amapá (UNIFAP). Destarte, a referência à História Medieval aparece através da inserção do Prof. Me. Renan Birro (UNIFAP), docente da instituição desde 2013. O grupo "Cultura e História das Ideias Políticas na Medievalidade"19, da Universidade Federal de Tocantins (UFT), foi formado em 2015 e tem como líder o Prof. Dr. Rodrigo Poreli Bueno, pesquisador que tem se orientado a pesquisar a sociedade medieval. Recentemente houve uma importante mudança ocorrida no "Grupo de Trabalho de História Antiga e Medieval na Amazônia" ${ }^{20}$ (GTHAM), fundado em 2014 e coordenado pela Prof. ${ }^{a}$ Dr. ${ }^{\text {a }}$ Roberta Alexandrina da Silva (UFPA). Este grupo tinha como particularidade ser o único que agregava pesquisadores de diferentes instituições da região, sendo responsável pela organização de encontros acadêmicos no ano de 2014. Em 2015, houve o término das atividades do grupo que passou a constituir o Núcleo Norte do Vivarium-Laboratório de Estudos da Antiguidade e do Medievo. Neste momento, o núcleo agrega professores da UFOPA, UFPA, UNIFAP, UFAM, UEA, UNIR, UECE, UPE e da Universidade da Guiana $^{21}$.

\section{Projetos e Perspectivas...}

Frente ao cenário pontuado até o momento, nos propomos a tecer algumas considerações sobre os projetos desenvolvidos entre 2014 e 2016 e, na medida do possível, lançar uma perspectiva para os próximos anos.

\footnotetext{
${ }^{17}$ A programação do referido encontro está disponível em: http://coloquioidademedia.blogspot.com.br (último acesso em 24/10/2015).

18 Disponível em: http://dgp.cnpq.br/dgp/espelhogrupo/8248868495966812 (último acesso em: 24/10/2015).

19 Disponível em: http://dgp.cnpq.br/dgp/espelhogrupo/9721811350386459 (último acesso em: 24/10/2015).

20 Disponível em: http://dgp.cnpq.br/dgp/espelhogrupo/3283571205395465 (último acesso em: 24/10/2015).

21 Disponível em: http://dgp.cnpq.br/dgp/espelhogrupo/3283571205395465 (último acesso em: 11/12/2015).
} 
Ao longo de 2014 foram dados os primeiros passos na direção de uma maior articulação regional. A ampliação do diálogo entre os professores teve como resultado a organização do I Encontro Internacional de História Antiga e Medieval da Amazônia, ocorrido no campus universitário de Bragança da Universidade Federal do Pará, sob a coordenação de professores da UFPA e da UNIFAP. O evento contou com a presença de pesquisadores de todas as regiões do país, somando sete universidades representadas (UFRJ, UFES, UFMT, UFRGS, UPE, UNIFAP, UFPA), doutorandos da Universidade de Leeds, além das conferências dos professores Dr. Ian Wodd (Leeds) e Dr. Alfonso Rodriguez (Buenos Aires).

Ainda em 2014, o IX Encontro Regional da Anpuh-PA conheceu a realização do "I Simpósio Temático de História Antiga e Medieval", igualmente uma expressão da articulação existente entre as universidades. Organizado por professores da UFPA, UFOPA e UNIFAP, o simpósio contou com comunicações, envolvendo graduandos, bolsistas de iniciação científica, mestres e doutores. No mesmo período ocorreu em Macapá-AP, o V Simpósio Internacional e VI Simpósio Nacional de Estudos Celtas e Germânicos: fronteiras, religiosidades, etnogêneses e monumentalidades. O evento contou com dois convidados internacionais, o Dr. Santiago Barreiro (CONICET) e a Me. Marion Poilvez (Universidade da Islândia), e com a presença de acadêmicos nacionais, respectivamente da UFMA, UFRJ, UFSC e USP.

Em 2016, foi realizado o II Encontro Internacional de História Antiga e Medieval da Amazônia \& II Encontro Nacional do Vivarium, na cidade de Santarém/PA, entre os dias 14 a 16 de setembro. Trata-se da primeira atividade promovida pelo núcleo Norte do Vivarium e contou com onze docentes, pós-graduandos e pesquisadores de diferentes instituições nacionais (UFAM, UEA, UFPA, UNIR, IFTO, UFMT, UEMA, UFBA, UFF), além do Prof. Dr. Rosuel Lima-Pereira, da Universidade da Guiana Francesa, como conferencista internacional.

É possível constatar uma ampliação na promoção de encontros dedicados a grande área de Antiga e Medieval, movimento que tem se pautado na tentativa de uma maior aproximação entre os docentes da região Norte, e entre esses e os pesquisadores de outras instituições nacionais e estrangeiras. Consideramos que essa aproximação, principalmente em âmbito regional, constitui o principal elemento capaz de favorecer o enraizamento de tais estudos na região. Nesse sentido, a criação do Núcleo Norte do 
Vivarium dá sinais de um amadurecimento dessa articulação, visto que o referido núcleo conta atualmente com a quase totalidade dos professores de Antiga e Medieval da região.

Não obstante, os desafios marcam a situação atual da História Medieval na região Norte. Mesmo com a ampliação do número de cursos de ensino superior e de professores concursados, termos como "pioneirismo" ou "desbravamento" ainda podem ser empregados para caracterizar o trabalho de tais professores na constituição da área. A própria extensão territorial da região, somada às dificuldades e aos altos custos de deslocamento terrestre, hidroviário e aéreo entre os estados, lança desafios à fixação de profissionais e ao estabelecimento de contatos frequentes entre as instituições de ensino. Quiçá, a ênfase na exploração de ferramentas de tecnologia da informação e comunicação (TIC) e a constituição de uma rede que agregue os profissionais possa favorecer a superação, mesmo que parcial, desse quadro de isolamento e de problemas de ordem logística. Outra barreira não menos importante a ser superada é a associação entre Antiga e Medieval como área única, prática que vai na contramão da especialização acadêmica vivenciada pelas áreas na última década e que acaba por contribuir para o reduzido número de profissionais na região.

Todavia, consideramos que os dois principais desafios são: a inserção e a consolidação da História Medieval em programas de Pós-Graduação; e uma maior abertura da região aos estudos que não se concentrem nos problemas e na história amazônica. As duas barreiras estão associadas e não se resolvem apenas no plano das instituições de ensino. Primeiramente, é indispensável que o exemplo da UFAM e da UFPA/Bragança se multiplique, porém, para isso, ao menos dois movimentos são necessários: a consolidação dos cursos recém-criados com a ampliação do quadro docente e que esses mesmos quadros tenham um número de doutores suficiente para a abertura de novos programas ${ }^{22}$. Sendo esses fatores resolvidos, caberia ainda superar o principal desafio da região, expresso na ênfase nos estudos regionais em detrimento da investigação acerca de outras áreas da História. Talvez seja esse fator um dos mais difíceis de ser modificado, pois acreditamos que ele está arraigado numa concepção de História que

\footnotetext{
${ }^{22}$ Nos últimos anos tem crescido no país o Programa de Mestrado Profissional (ProfHistória), programa stricto sensu em formato semipresencial direcionado ao Ensino de História. Em vista das exigências diferentes para a criação do ProfHistória e dos programas tradicionais, assim como do investimento governamental na formação de professores, cabe observar nos próximos anos até que ponto esse cenário vai incidir sobre a institucionalização dos novos cursos da região Norte na conformação de seus programas de Pós-Graduação.
} 
estabelece uma hierarquia entre conhecimentos históricos mais ou menos "úteis" frente aos desafios contemporâneos e locais ${ }^{23}$. Nesse sentido, por que estudar a Idade Média na Amazônia?

Sem vislumbrar um aprofundamento de uma temática tão delicada, fazemos referência aos apontamentos de Marcelo Cândido da Silva. Ao considerar as justificativas para o estudo da Alta Idade Média no Brasil, o autor chama atenção para a questão das "origens medievais" do mundo moderno e da sociedade brasileira, elemento que serve de argumento para que o medievalista explique aos compatriotas e aos colegas europeus a utilidade de seu trabalho. No entanto, após elucidar tal postura, Silva avança em criticalas, notando como a perspectiva das "origens" e das "continuidades" criam novos problemas para o historiador e podem constituir leituras teleológicas do passado medieval, construindo proximidades e permanências ao passo que ofuscam as alteridades existentes entre a Idade Média e a sociedade contemporânea ${ }^{24}$. Partindo das considerações do autor, acredita-se que uma possível justificativa para os estudos medievais na Amazônia não deve repousar na procura das heranças medievais presentes na história da região, ainda que narrativas de viagens, mitos como o messianismo sebastianista, ou mesmo a musicalidade e a religiosidade apontem nessa direção. Destarte, preferimos pensar tal justificativa por um viés diferente, entendendo que o homem em sociedade, seja essa sociedade qual for, constitui o objeto final da pesquisa histórica, e, assim, favorecer o estudo da História Medieval e de todas as demais áreas que compõem os domínios de Clio.

\footnotetext{
${ }^{23}$ Sobre a presença dessa variação no âmbito da História no Brasil, ver: ALMEIDA, Néri de Barros. L'histoire médiévale au Brésil: du parcours solitaire à l'inclusion dans le champ des sciences humaines. In: MEHÚ, Didier, ALMEIDA, Néri de Barros \& SILVA, Marcelo Cândido da (dir.) Pourquoi étudier le Moyen Âge? Les médiévistes face aux usages sociaux du passé. Actes du coloque tenu à l'Université de São Paulo du 7 au 9 de mai 2008. Paris: Publications de la Sorbonne, 2012, p.125-143.

${ }^{24}$ SILVA, Marcelo Cândido da. Pourquoi étudier le haut Moyen Âge au XXIe siècle, au Brésil? In: L'histoire médiévale au Brésil: du parcours solitaire à l'inclusion dans le champ des sciences humaines. In: MEHÚ, Didier, ALMEIDA, Néri de Barros \& SILVA, Marcelo Cândido da (dir.) Pourquoi étudier le Moyen Âge? Les médiévistes face aux usages sociaux du passé. Actes du coloque tenu à l'Université de São Paulo du 7 au 9 de mai 2008. Paris: Publications de la Sorbonne, 2012, p.197-214. Sobre os elementos destacados do texto de Silva, ver, por exemplo, as justificativas apresentadas por José Rivair Macedo ao discutir o ensino de História Medieval (Repensando a Idade Média no Ensino de História. In: KARNAL, Leandro (org.). História na sala de aula. Conceitos, práticas e propostas. São Paulo: Contexto, 2008, p.109-125). Acerca da ruptura entre o passado medieval e o mundo contemporâneo, consideramos emblemáticas as afirmações de Alain Guerreau em El futuro de un pasado. La Edad Media en el siglo XXI. Barcelona: Crítica, 2002.
} 


\section{Considerações finais}

Em vias de conclusão, retomam-se os principais apontamentos do texto. Em primeiro lugar, a constituição da área de História Medieval no Brasil tem uma trajetória recente, sendo os anos 80 o período comumente aceito como época que expressa a afirmação da área. Atualmente, constam inúmeros grupos de pesquisa, publicações em português, periódicos especializados e profissionais formados com mestrado e doutorado dedicados ao medievo. Todavia, esse cenário não pode ser generalizado para todo o país, sendo marcantes as diferenças existentes entre o Centro-Sul e a região Norte. Universidades criadas na última década contam com um ou, no máximo, dois professores responsáveis pelo ensino de História Antiga e Medieval e são, em parte, de fundação deveras recente. Esse é o quadro comum da região, ainda que os casos da UFAM e da UFPA sejam exceções pela longa trajetória de seus cursos.

Outro fator que foi possível evidenciar é a quase ausência de programas de Pósgraduação da região amazônica com a presença de medievalistas, elemento que também constitui um limitador para o avanço da área. Nesse sentido, a superação dos desafios enfrentados pela História Medieval na região amazônica envolve problemas diversos, como a necessária ampliação dos cursos de Ensino Superior e dos programas de PósGraduação e a contratação de novos docentes.

Ao longo do texto, concentramos a atenção nos aspectos institucionais buscando apontar caminhos para a superação desse quadro. Não obstante, ao enfatizar que a inclinação aos estudos regionais também constitui uma importante barreira para a ampliação da História Medieval na região, consideramos que este aspecto ultrapassa a questão institucional ou as particularidades regionais, envolvendo, diretamente, a posição dos estudos medievais no campo da História e das Ciências Humanas, posição questionada atualmente tanto no Brasil como em outros países. Deste modo, as circunstâncias que caracterizam os desafios da História Medieval na Amazônia são expressão de um cenário que atinge toda a área em diferentes regiões.

Ao constatar o predomínio de cursos de licenciatura na região Norte e que a área de História no Brasil tem se orientado institucionalmente pela formação de professores, sem desconsiderar toda a demanda social relacionada aos profissionais da educação, acreditamos que a aproximação das preocupações das pesquisas em História Medieval 
com as questões do ensino de história pode ser uma via para a superação das resistências acadêmicas e institucionais. Assim, a resposta ao porquê estudar História Medieval na Amazônia passa igualmente pela resposta ao porquê estudar História Medieval numa formação voltada ao ensino na educação básica.

O debate em torno da BNCC gerou uma série de posicionamentos em defesa dos estudos antigos e medievais, contudo uma parte significativa dos argumentos defendeu a História Antiga e Medieval com justificativas fundadas na tradição das áreas e na qualidade das pesquisas em desenvolvimento no país. No que pese a relevância destes argumentos, ainda é necessário amadurecer a reflexão sobre a justificativa social das áreas, discutindo, por exemplo, as contribuições da História Medieval para a formação histórica e pedagógica. Em termos de como essa aproximação pode ser feita e dos resultados dessa orientação, os trabalhos dos professores Dr. Nilton Mullet Pereira (UFRGS) e Dra. Edlene Oliveira Silva (UnB) servem de indicativos da potencialidade da Idade Média para o ensino de história.

Ao ressaltar a importância de pensar a História Medieval relacionada à formação de professores, o porquê estudar História Medieval na Amazônia torna-se ainda mais complexo. Durante o II Encontro Internacional de História Antiga e Medieval da Amazônia (2016), o professor Macário Carvalho Júnior - atualmente o único docente formado em um dos programas de pós-graduação da região - levantava em uma das sessões a reflexão sobre as particularidades de se estudar o medievo na Amazônia, sugerindo que esta questão poderia reorientar a área respondendo aos desafios regionais internos e externos ao meio acadêmico. Tal problemática não foi o foco de nosso estudo e demandaria discussões que ainda precisam ser travadas pelos pesquisadores da região. No entanto, a própria existência desta preocupação serve de indicativo que a História Medieval pretende justificar-se na Amazônia por diferentes vias.

Ainda que marcado por inúmeros desafios, o cenário atual apresenta sinais de que o quadro está em mudança, e talvez a maior expressão dessa via seja as ações de cooperação entre os professores da região. Portanto, acreditando que nos próximos anos será possível tecer um balanço mais positivo, gostaríamos de concluir fazendo referência à célebre frase do poeta romano Terêncio: "Homo sum: nihil humani a me alienum puto". Espero que os medievalistas e os estudos medievais aprofundem suas raízes na região 
Revista Signum, 2017, vol. 18, n. 1.

amazônica posto que, como historiadores, o homem em qualquer temporalidade não nos é estranho.

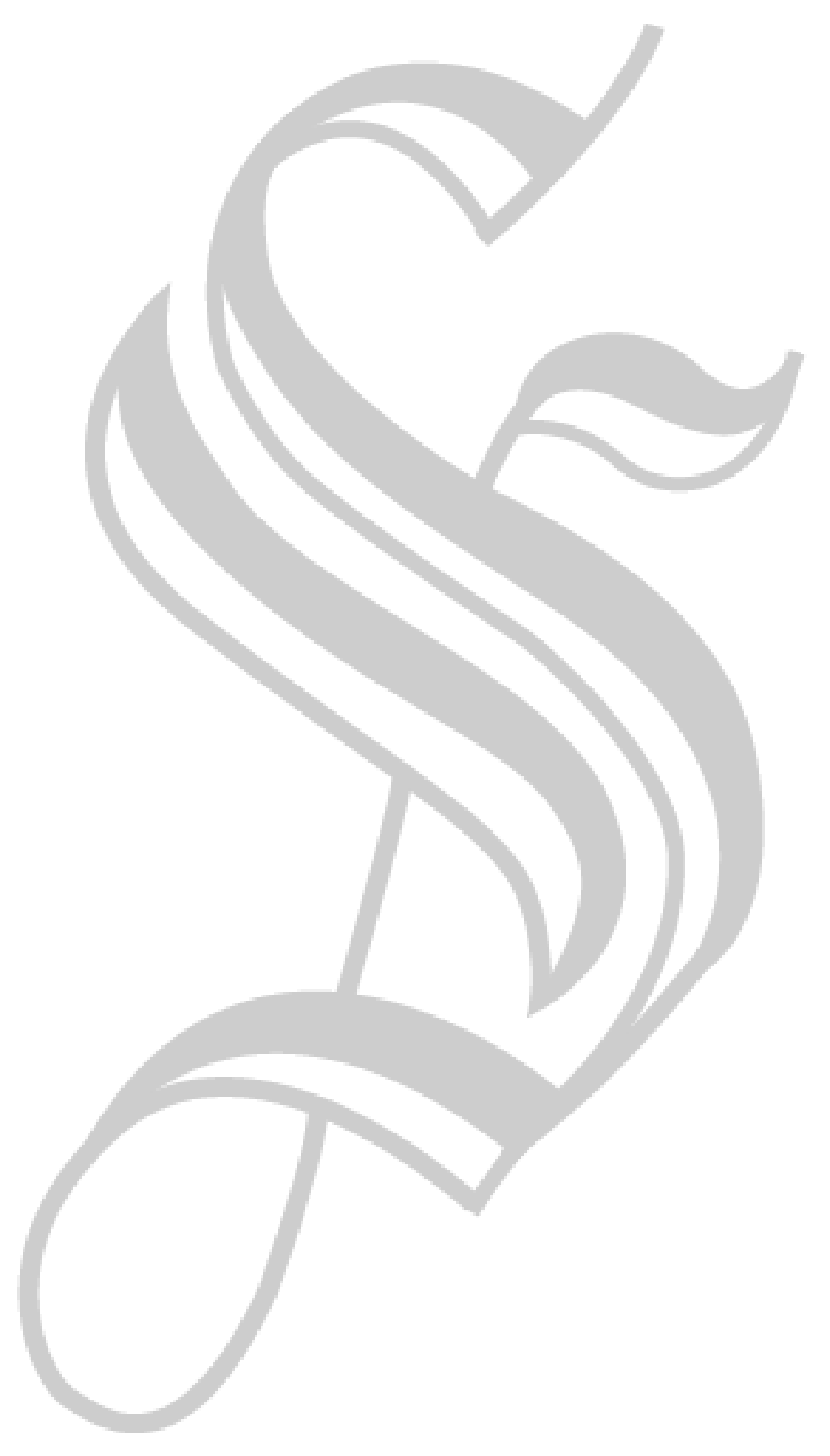

